\title{
Anne Marie Olesen
}

\section{The Concept of (Aesthetic) ${ }^{x}$ Experience in Gadamer's Hermeneutics and its ANTHROPOLOGICAL IMPLICATIONS}

\section{I: GADAMER'S CONCEPT OF EXPERIENCE AS AN EXPERIENCE}

In Trutb and Method Gadamer introduces a concept of experience (Erfabrung in German) which is different from and in a sense richer than the notion of experience established in the natural sciences and especially in the tradition of British empiricism. Although this tradition emphasized experience as the source and ultimate criterion of knowledge, its critical concern with validated knowledge led, according to Gadamer, to a preoccupation with methods which "attempt to guarantee, through the objectivity of their approach, that these basic experiences can be repeated by anyone." The concept of experience established in the natural sciences thus focuses on the repeatability of procedures and results, on the confirmation that one experience is able to give another. What is lost in this narrow notion of experience is, according to Gadamer, its "inner historicity." Gadamer claims that this tendency, for which Aristotle remains the best witness, over-emphasizes one feature of experience, and that it needs to be contested by drawing attention to other aspects of experience.

Gadamer points to another feature by referring to Aristotle's famous battleground image (Posterior Analytic 2.19). The image pictures a fleeing army that brings itself to a standstill when first one man and then another makes a halt - until eventually it comes together again in a united front, amenable to a single principle or a single command (arche). Aristotle applies this image in

1 I bracket the word aesthetic in order to indicate that experience is not confined to aesthetic experience (by which Gadamer means the experience of art), even though the experience of art is a central instance.

${ }^{2}$ Hans-Georg Gadamer, Wabrbeit und Methode (Tübingen: J.C.B. Mohr, 1986), 330. 
explaining the emergence of a coherent experience out of a succession of perceptions, and the gradual consolidation of this experience into universal concepts. Gadamer, on the other hand, sees the image as the paradigmatic illustration of the acquisition of experience as an uncontrollable, unforeseeable and ultimately opaque process. Gadamer thus criticizes Aristotle for having a teleological notion of experience. Concepts are regarded as the telos, or the proper outcome, of experience, and thereby its character as a process is overlooked.

What is significant in experience as a history or process is the negative element, which gives it a dialectical structure. Against the conglomeration of experience out of an uninterrupted succession of particular impressions suggested by Aristotle, Gadamer, under Hegel's guidance, sees a tension between our established - scientific or everyday - experience and a new experience. A new experience is always negative. A new experience only occurs through the negation of previous experience and does not consist in a simple confirmation of previous experience. So strictly speaking, we cannot have the same experience twice. It is part of the nature of experience to be continually confirmed; it is, as it were, acquired only by being repeated. But it is no longer a new experience when it is repeated and confirmed. The same thing cannot again become a new experience for us; only something different and unexpected can provide someone who has experience with a new one. The negativity of experience has a productive meaning though. It is not simply that we see through a deception and hence make a correction; rather we acquire a comprehensive knowledge: "We cannot, therefore, have a new experience of any object at random, but it must be of such a nature that we gain better knowledge through it, not only of itself, but of what we thought we knew before - i.e. of a universal." 3

Experience in this sense is something that one "has." It is that kind of vivid, heightened or emphatic experience that imposes itself on us (and finds expression in a phrase like "that really was an experience") precisely by interrupting the: customary course of events. This kind of experience is marked by an extraordinariness, by a power to take us out of the flow of the everyday. But, on the other hand, as it remains positively and significantly related to the context which itt interrupts, it is peculiarly suited to revealing or changing this context. Neww experiences do not only give us access to a new reality but also involve us in amending and reshaping our previous apprehension of reality.

\footnotetext{
${ }^{3} \mathrm{Ibid},, 335$.
} 
The kind of experience vindicated by Gadamer can be articulated with reference to the notion of a learning experience. We learn from this sort of experience because it serves to negate our previous views and because it cannot be repeated. Indeed what we learn through experience in this sense involves such a radical transformation of our views that we cannot go back to them to re-experience the experience of their negation.

But how can this kind of experience be a learning experience if it cannot be repeated? Doesn't learning from experience require that experiences can be repeated? To give a rather simple example, don't I learn not to get too close to fire by repeatedly having experienced that I'll get burned?

In what follows, I want briefly to elaborate on the relationship between experience as an experience (in the emphatic sense) and learning by turning to Joseph Dunne's account of the connection between experience, pbronesis and character in the work of Aristotle.

\section{2: EXPERIENCE AS THE SYNTHESIS OF PHRONESIS AND CHARACTER}

In his book Back to the Rough Ground Joseph Dunne offers an analysis of Aristotle's concepts of phronesis and tecbne that on some significant points differs from traditional interpretations. As Dunne himself states, Gadamer's adoption of the concept of pbronesis and his conception of experience, influence this analysis a great deal. Hence the central position Dunne assigns to the concept of experience in the analysis of Aristotle does not reflect Aristotle's account but is rather expressive of the influence of Gadamer. On the other hand, Dunne's account of Gadamer is, I believe, informed by his somewhat untraditional reading of Aristotle. This mutual elucidation between Aristotle and Gadamer is, I think, very fertile both with regard to Aristotle's categories and the concept of experience in Gadamer's hermeneutics.

As opposed to episteme, or theoretical knowledge, both phronesis and techne are usually referred to as practical knowledge. What distinguishes techne and pbronesis is, on the surface, that techne is related to the practical sphere of poiesis or production, while pbronesis has to do with the conduct of one's life and

4 Joseph Dunne, Back to the Rough Ground (Notre Dame: University of Notre Dame Press, 1993). 
affairs as a citizen of the polis. Thus techne is the kind of skilled knowledge possessed by the craftsman, while phronesis is the kind of knowledge possessed by a person who knows how to live well. What further distinguishes tecbne and phronesis is that techne can be taught and learned by means of instructions. I can learn how to fix a motorcycle or build a summer house by way of instructions from someone who knows how to do it - or in a more contemporary version by reading and following the instructions in one of these "How to..." books. Pbronesis camnot be taught and learned in a similar way. But how then does one learn, if phronesis cannot be taught by means of instructions? How does one become a pbronimos? In the course of answering this question Dunne points to an interesting circularity between phronesis and character in Aristotle's work. As Aristotle himself puts it: "It is not possible to be good in the strict sense without phronesis nor phronetic without moral excellence". 5 It is not the case that one is first of good character, and then can have pbronesis. Rather, being phronetic is itself part of what it means to be of good character. A virtuous character is the disposition that grows out of the repeated performance of good acts - and then becomes itself a motivating source of good acts. But goodness is only to be ascribed to acts that are mediated through an already established character. It is at the transition between good actions prompted by an innate virtuous character (which all human beings to some extent possess) and actions that spring from and are an expression of character, that phronesis arises. If one has reached the stage of a stable, virtuous character, then one will be found already to possess phronesis as well.

As to the circularity between phronesis and character, Dunne concludes with a thesis according to which pbronesis and character are moments in the more comprehensive process of experience. Or to put it in another way, the concept of experience is a synthesis of the concepts of phronesis and character.

The close relationship between experience and character unfolds in Aristotle's analysis of the statesman. What characterizes the good statesman is that he is capable of applying his knowledge of universal principles with 'an eye' and a sensitixity for what the particular situation requires and with special reference tor the good life for the individual citizen as well as the community as a whole. This: requires experience. A young man has no experience; and it makes no difference whether he is young in years or youthful in character. So the lack of experience that is in question here is really a lack of character.

\footnotetext{
${ }^{5}$ Ibid., 279.
} 
The connection between experience and character can be more systematically determined by assigning to character the same place that Aristotle assigns to experience in his outline of the inductive process. The initial impressions that lead to ethical (and not merely cognitive) development are not simply sense impressions of the external world but are rather impressions of one's own praxis or actions. When one performs good acts one undergoes these acts, or experiences them. Now repeated experiences of them and reflection upon them give experience understood as that which constitutes character. So character is experience.

Those experiences that lead to formation of character are one's impressions of and reflection upon one's own actions. Thus experience is tied to action. Although the good statesman functions as the ideal example of an experienced person, a phronimos, it is not sufficient for the young person just to observe this model. Without actually having experience of the actions with which politics is concerned, the young person will not become experienced.

But what now is the connection between experience and pbronesis? Dunne interprets the connection between character and experience in such a way that to be of character is to be experienced and vice versa. But experience (or to be an experienced person) is not a static state; it is not a completed state of knowing that can be made the object of instruction. The dynamic aspect of experience is expressed by phronesis. Phronesis is a perfected form of experience in that it is phronesis which makes experience not just the accumulated systematization of one's past actions and impressions, but " $\mathrm{a}$-dynamic orientation to bring this systematization into play and allow it to be tested by present circumstances". 6 Phronesis is the intellectual virtue through which the experienced person exploits his experience and in the process further develops and refines this experience. Pbronesis is what enables experience to be self-correcting and to avoid settling into mere routine.

\section{3: EXPERIENCE IN THE GENUINE SENSE: HUMAN FINITUDE}

Now I turn to the question of how this discussion of Dunne can help us elucidate Gadamer's notion of experience as an experience.

${ }^{6} \mathrm{Ibid} ., 305$. 
It follows from the connection between experience and character that in becoming experienced one has been involved not only in acquiring information, but also; through this very acquiring, in a process of self-formation. It follows from the connection between experience and pbronesis that being experienced consists in being open to the possibility of being affected by new experience. Experience always brings with it an element of surprise, and to be experienced doess not mean to have had one's surprises so that one is now proof against new ones, but, on the contrary, to have learned to be at home with the possibility of surprise as a permanent possibility inseparable from historical existence itself.

To be experienced is to have had experiences, to possess experience, but it also involves being prepared to learn from new experiences. Pbronesis is a habit of attentiveness that makes the resources of one's past experience flexibly available to one and, at the same time, allows the present situation to "unconceal" its own particular significance - which it may do by evincing as an insight which, while it could not occur without one's past experience, still transcends, and so enriches, it. To be experienced is thus a formed disposition only insofar as one is capable of continually renewing one's experience.

Although Gadamer appeals to Hegel as his important witness for the dialectic of experience, he nonetheless resists Hegel's conclusion that this dialectic must end in the achievement of an absolute knowledge. Instead of thinking of experience in such a way that experience itself is overcome, transformed into the absolute self-consciousness, as Hegel does, Gadamer sees it as resulting not in greater knowing, but in an openness to more experience.

To clarify and deepen the scope of the notion of experience, Gadamer gives an interesting analysis of Aeschylus' use of the phrase "to learn from suffering." Aeschylus, Gadamer argues, means to go beyond saying that failures and negative experiences can lead to wisdom and to the right course of action. Though the platitude normally suggests this message, Aeschylus means to show that the truly experienced person is one who, in acknowledging the ineluctability of experience and the limits of definitive knowledge, has gained insight into the finite nature of his own existence. In the most genuine sense, to experience, or to be experienced, means to know that one is finite. 


\section{4: Aesthetic experience as embodied eXPerience}

Even though Gadamer does not explicitly thematize the body in the context of experience, it is intuitively obvious that the body is involved (Gadamer does theorize the body in the book called The Enigma of Health, but it is not of much help here).

I want now to give an example of how I think the body contributes in creating this vivid or heightened experience of which the aesthetic experience is an essential instance.

A few months ago I saw for the first time a photo by Cindy Sherman (Untitled \#153, 1985). This is a photo of Cindy Sherman taken by Cindy Sherman, i.e. it's not a photo of a corpse but a photo in which the artist made herself up to look like a corpse. My experience of exactly this photo (of and by Cindy Sherman) was an experience in the Gadamerian sense because it made a profound impression on me. On the surface level it changed me in the way that it reshaped my sense of how one can use one's own body in art and what it means to do so. But the reason why I call this experience an experience is that it had a much deeper impact on me. Emphatic experiences have an ability to haunt us, which an experience understood as Erlebnis, as an entertaining experience which one is done with almost as soon as it ends, doesn't have.

I think in this context it is appropriate to refer to Freud's notion of the uncanny (I'm using the term as a translation of the German word "unheimlic"). In his essay "Das Unheimliche" Freud draws attention to a contrast in the original meaning of the term "beimlicb": it simultaneously means "the familiar" and "the secret" or "the concealed". The same goes for the counter term "das Unbeimliche". As the counter term of "das Heimliche", "das Unbeimliche". is simultaneously the counterpart of the familiar and the counterpart of the secret or concealed, which means that is it is simultaneously unfamiliar and unconcealed (or simply visible). "Das Unbeimliche" keeps oscillating between these opposite meanings of the term, and hence it is marked by an undecidability.

Even though Freud doesn't ascribe "das Unheimliche" to objects, but to the psychological state of the spectator, I think it is reasonable to characterize the experienced object in terms of indeterminacy or incomplete transformation. Cindy Sherman draws - in the context of experience - upon this principal 
undecidability by simultaneously being "dead" and "alive". In that way the photo disturbs or interrupts the way one normally orders or categorizes the world.

And to, push the point a little further - that someone is alive but makes herself look dead and takes a photo of herself as "dead" is in a sense a subtle allusion to the genuine object of experience, namely human finitude.

Of course my body helped in creating this experience. I felt a kind of bodily disgust along with fascination in seeing the photo - comparable for example, to the way I can actually feel the pain in my body when reading a novel in which people get physically hurt. And this disgust was certainly a part of what made me bave an experience with the photo. The point I'm trying to make is thatthis bodily action - I'm using the term action as opposed to reaction in orden not to suggest, that the bodily part of experience is temporally later than the mental response; rather the mental response is tied in with a bodily response - this bodily action or happening was a part of what the artwork meant to me. Experience is not a mere mental act; the body is involved.

But what kind of body? What conception of the body does Gadamer's account of aesthetic experience as an experience commits one to support? What concept of the body is implied in the context of experience? Or, to be less ambitious: what conception of the body is not?

I want to reject two current proposals for a conception of the body discussed in relation to experience, learning and perception. One is the body conceived of as the physical body, the other one is the body conceived of as the lived or living body.

The German language (and Danish too) offers two different expressions for the word "body", Körper and Leib, which correspond to these two conceptions of the body. Körper refers to the biological-somatic body, to the body as a physical object, as something which is susceptible to objectification and processes of measurement (this is Gadamer's own definition). Leib, on the other hand, is associated with "life" (Leben or Leiben), and thus refers to the body conceived of as the lived or living body.

What I find interesting here is not the distinction itself but rather what one makes of it, and that is how one characterizes Körper as opposed to Leib and, conversely, Leib as opposed to Körper, and what ontological status one assigns to Körper and Leib respectively.

Among current researchers in the field of non-scholastic learning and cognitive science, who claim to have re-discovered the body in relation to expe- 
rience, learning and perception, the body is conceptualized and described as the physical body specific for the human race or as our native kinetic-kinesthetictactile competence and is posited as "the originating ground of our knowledge, our capacities, and indeed, of our very being"?

Not directly opposing this particular conception of the body but at least challenging the concept of the body as a physical object, some commentators of Heidegger and Merleau-Ponty posit the lived or living body as the origin of the physical body or as the ontological condition of the body interpreted in physi-. cal or biological terms. ${ }^{8}$

The reason why I want to reject the two above-mentioned conceptions of the body as candidates for the concept of the body implied in experience (in the emphatic sense) is that they are both posited as foundations. In the former case the physical, biological or somatic body is posited as the foundation of our very being. In the latter, the alleged counter term (of the concept of the body as physical), the lived or living body, is hypostatized and, I believe, thereby also mystified, as the origin or foundation of the physical body. And what I think this means is basically just to substitute one foundation for another.

I do find it reasonable, in the context of experience, to apply the notion of the lived or living body but only as a term indicating that there is no body in-itself. The body is tied in with a mental response and a situation, the body is always understood, interpreted or experienced. The lived or living body is how one experiences the world with one's body and the way one experiences the body. This is historically and socially shaped, it changes in the course of time and is shaped by the particular situation one finds oneself within. And how we live our lives with our bodies or how we experience the world with our bodies is just one of the ways our possibilities as human beings manifest themselves to us. Thus it is not in accordance with Gadamer to assign ontological priority to either of the proposed concepts of the body (as opposed to the other), nor to the body as opposed to the mental.

7 Maxine Sheets-Johnstone, "On Learning to Move Oneself: A Constructive Phenomenology", Working Papers No. 4, 1999, 9.

${ }^{8}$ See Sune Frølund, "Sexualontologi", Pbilosopbia 1989:17, No. 3-4, 50. 


\section{5: Concluision}

Contrary to what the title of this paper might suggest, the Gadamerian concept of experience is not confined to the area of aesthetics. Yet the aesthetic experience (and that is the experience of art) does form an exemplary instance of emphatic experience: "Aesthetic experience is not just one kind of experience among others; but represents the essence of experience per se."

It is intuitively obvious that the body is involved in creating this kind of experience. The body contributes to turning an experience into an experience. In fact I dowwant to suggest that without the bodily response - which is neither prior to non subsequent to the mental response - my experience with the Sherman photo wouldn't have been an experience.

Yet my point in picking exactly this photo is not to suggest, that the 'experience of human finitude, which lies at the core of every emphatic experience, can be explained by or based on our bodily finitude. That would be to succumb to the idea that our physical-somatic-biological body constitutes the foundation off our being. To be experienced is to have insight into the historicity and fallibility of human beings.

${ }^{9}$ Hans-Georg Gadamer, Wabrbeit und Metbode, 66. 